\title{
"Hoje preciso refletir um pouco": ser social e tempo histórico na obra de Chico Buarque de Hollanda - 1971/1978
}

M arcos NAPOLITANO ${ }^{1}$

RESU Mo: Este artigo analisa a relação entre o ser social e o tempo histórico em cinco canções compostas por Chico Buarque de $\mathrm{H}$ ollanda durante os anos 70, em plena vigência do regime militar no Brasil. Nossa perspectiva é a de que a obra deste compositor revela uma singular articulação entre aquelas duas categorias, expressando váriasformas de consciência crítica em relação à experiência da opressão e do esvaziamento do espaço público. Procuramos demonstrar, a partir dos exemplos musicais propostos, que Chico Buarque fez da relação tensa entre ser etempo num contexto autoritário, a base de sua matéria poética e, desta forma, imprimiu um sentido político sui-generis para a sua obra, indo além dos limites da canção de protesto tradicional.

Palav Ra S-chave: M PB: Chico Buarque; música epolítica; regimemilitar: aspectos culturais.

O poema remete ao tempo, não apenas por aquilo que fala, mas também pela estrutura, pois fazer poemas é organizar palavras no tempo. A matéria e estrutura poética (fonema, palavra, verso, métrica, ri$\mathrm{ma}$ ), organizadas conforme um determinado ritmo, remetem ao tempo como categoria fundamental do poema, formando ereformando a consciência do ser no tempo (seu tempo, outro tempo, novo tempo, não-tempo). Assim, Alfredo Bosi discutiu as relações entre o ser e o tempo na poesia, ${ }^{2}$ tendo em vista a perspectiva da resistência contra a opressão vigente. Para ele, o ser, filosoficamente falando, se define pela consciência e, portanto, pela poesia. A consciência, por sua vez, impli- 
ca a consciência do tempo. Por uma associação lógica, conclui-se que o poema remete ao tempo.

Toda esta reflexão, nascida durante a ditadura militar brasileira, acabava levando o autor a uma relação necessária entre poesia e resistência (política, cultural, existencial):

Diante da pseudototalidade forjada pela ideologia, a poesia deverá ser feita por todos, não por um (...). Essa "ser feita por todos" não pode se realizar materialmente, na forma de criação grupal, já que as relações sociais não são comunitárias. M as acabou fazendo-se de algum modo, como produção de sentido contra-ideológico, válida para muitos³.

A resistência na forma de poema, para Bosi, apresentava muitas faces: nostálgica, crítica ou utópica. Esta tipologia inspiraria um dos primeiros trabal hos sobre a relação entre poesia, história e política na obra de Chico Buarque de H ollanda, escrito por Adélia M eneses. ${ }^{4}$ Para a autora, a obra de Chico Buarque poderia ser divida em duas vertentes:

- lirismo nostál gico - ontem - tempo mítico;

- canções da repressão - assume o tempo histórico, seu tempo. I mperativo e não escolha. 0 poema não apenas expressa a semântica da repressão, mas também a sintaxe da repressão, pois a censura e repressão introjetadas tornam-se estruturais nas canções desta época.

N esta segunda fase, Chico operaria em duas vertentes: utópica, cantando o amanhã libertado de opressão e crítica, o hoje opressivo a ser denunciado. Assim, a autora tentava explicar uma das sensações mais fortes na experiência de audição das canções de Chico Buarque entre os anos 60 e 70, enfatizando o tempo como a matéria central da sua poética, em dois níveis: o tempo que dilui as experiências do ser, tempo da nostal gia, tema recorrente sobretudo no primeiro momento da obra chicobuarquiana (1966-1970); e o tempo que modifica o ser (e o mundo), o tempo da utopia.

Heloisa Starling vê na obra de Chico Buarque um "caráter forte- 
mente artesanal de uma obra preocupada, especialmente, em reinvestir a palavra da plenitude de suas potencialidades, não importando no caso, o gênero ou a forma utilizada". ${ }^{5}$ Segundo ela, Chico potencializa um traço específico da canção popular brasileira:

Sua força narrativa, vale dizer, a prioridade dada pela canção a uma forma de escritura do tempo que concentra, em si, de maneira paradigmática, os paradoxos característicos da nossa modernidade - o reconhecimento do fim das formas seculares de compartilhamento da palavra transmitida de pai para filho e a reafirmação da necessidade política e ética de uma outra escritura da história capaz de extorquir do fluxo do tempo as formas e os contornos arruinados de eventos do passado. ${ }^{6}$

O "seresteiro, poeta, trovador", como o próprio compositor se define em uma de suas canções, seria um "entre-lugar construído pela articulação entre a tradição letrada, tradição escrita e a tradição oral da poesia cantada no País." ' Starling também sublinha a importância do tempo como matéria poética do compositor. Assim, Chico Buarque faz

aflorar no tempo os sons do que foi abandonado, eclipsado, anulado na experiência nacional brasileira - e, ainda assim, está lá, uma espécie de sons que se encontram perdidos na escuridão do passado, sons que libertam os homens de seus hábitos presentes e desamarram as correntes que prendem o futuro. ${ }^{8}$

Dentro desta tradição de análise, vamos propor outras considerações para analisar a relação entre o ser e o tempo na obra chicobuarquiana, enfatizando as chamadas canções de repressão (1971/1978). Como hipótese central, sublinhamos que esta fase da obra de Chico Buarque é marcada pela tensão básica entre não-ser (entendido como a produção do silêncio e diluição da atuação crítica produzidos pela repressão) - entidade fantasmagorizada no não-tempo da história (a "noite" como imagem-síntese da ditadura, tempo de imobilidade emedo) - versus poesia e música (suas antíteses). 0 simples ato de cantar, potencializando o ritmo e a melodia das frases poéticas, redefine não 
apenas o sentido convencional das palavras, mas sua expressividade latente e sutil, podendo desencadear inúmeras reações no ouvinte, independentemente do conteúdo da letra veicular qualquer tipo de "protesto" político. Chico, dessa maneira, adensava a "rede de recados" contra a ditadura, tal como foi sugerida por José M iguel Wisnik. ${ }^{9}$

Contra a repressão e a censura, um dos recursos, não apenas deChico, mas de vários compositores, era trabalhar a poética do ser e do tempo e suas antíteses, produzidas pela experiência da repressão, a saber: não-ser (silêncio-censura) enão-tempo (ditadura-exílio-imobilismo político). Neste sentido, mais do que um compositor contrário à ditadura, Chico foi um cronista da dramática modernização brasileira, potencializada pela própria ditadura. 0 progresso técnico que, mesmo benéfico, atropela todos os sonhos e fantasias, tornava-se mais cruel quando imposto a partir de um modelo político autoritário e excludente.

Antes de analisar algumas canções, vamos discutir um pouco mais o lugar que Chico Buarque ocupava na cultura brasileira dos anos 70. Surge aqui uma questão fundamental: por que Chico teria se transformado em uma unanimidade nacional, se tão perseguido pelo regime militar? Não basta, na nossa perspectiva, a resposta básica de que, justamente por ser perseguido, tornou-se um paladino da resistência. Isto responde em parte ao problema. Em primeiro lugar, arriscamos dizer que sua popularidade estendia-se para além do sucesso junto ao público-padrão idealizado pela memória como o ouvinte de M PB por excelência ("jovem-intel ectual-classe média-estudante-esquerdista"). Parece haver, nas canções de Chico Buarque, algum elemento que conseguia expressar um sentido de resistência e uma nova proposição acerca da relação ser/tempo que ia além da instrumentalidade política imediata, típica das canções de protesto contra o regime.

Havia também um outro elemento estrutural explicativo, queajuda a entender o lugar social do compositor. Chico era um dos nomes mais valorizados pela indústria fonográfica, e sua função de paladino contra a ditadura era valorizada por essa mesma indústria, embora o jogo fosse muito perigoso. ${ }^{10} \mathrm{~A}$ tensão de veicular canções dentro da indústria fonográfica, altamente capitalizada, e poder exercitar sua liberdade criativa causavam-Ihe uma estranha situação, ainda pouco estu- 
dada: enquanto a faceta cancionista de Chico Buarque cumpria seu papel de vendedor de cultura, sua faceta dramaturgo e escritor tentava desenvolver projetos mais autorais e ousados, sem as amarras do grande mercado ou da vigilância mais detal hada da censura. Lembramos que além de dramaturgo, autor de Roda viva, Calabar e Gota D'água, ainda nos anos 70 Chico Buarque iniciou sua carreira de escritor, com o livro Fazenda modelo (1974).

Voltemos às canções. Não obstante compartilharmos da tipologia da poética política de Chico Buarque, proposta por Adélia M eneses (nostalgia / crítica / utopia), sublinhamos que as três dimensões do tempo correspondente - ontem - hoje - amanhã - não se anulavam, mas faziam parte da estilhaçada identidade do ser no tempo (no caso, o ser social em questão era materializado pelo cidadão brasileiro no contexto autoritário dos anos 70). Suas canções não apenas denunciavam o regime militar, mas os efeitos da violência e da repressão sobre as consciências. N este sentido, não se tratava de fazer uma música de protesto, no sentido estrito da exortação a uma ação política efetiva e prática, mas afirmar uma experiência sóciocultural, ainda que fugaz, de liberdade e "promessa de felicidade" que durava na exata medida da própria experiência da canção. ${ }^{11}$ M uito da melancolia presente nas letras das suas canções provém da percepção de que a canção - não somente promessa, mas estado de felicidade, ao ocasionar o breve reencontro entre o ser e o tempo - é, no fundo, finita e impotente contra o mundo real. Mas o próprio compositor nos responde a este dilema: "é melhor sofrer em dó menor, do que sofrer calado".

Tanto o cancionista quanto o público querem se agarrar ao objeto fugaz - a canção - resultando desta experiência breve a melancolia, que não é apatia e indiferença diante do mundo, mas, como dizia Walter Benjamin, um estado potencialmente crítico produzido pelo mal-estar da modernidade. ${ }^{12}$ Só aquele ser que se recusa a esquecer, a aceitar o presente eterno e sem qualidade, quando "tudo que é sólido se desmancha", pode construir o futuro.

Com base neste conjunto de proposições em torno da relação ser/tempo vamos analisar a matéria poético-musical de cinco canções deChico. 


\section{CONSTRUÇÃO}

Numa associação livre com a obra clássica de Machado de Assis, poderíamos definir a música Construção como as "memórias póstumas de um operário". Composta e gravada no início dos anos 70, esta canção deu nome ao álbum, lançado em pleno refluxo dos sonhos libertários da década anterior, radicalizando a relação "não-tempo/não ser" como matéria poética. 0 operário desumanizado da construção, vítima da monotonia, do mecanicismo dos movimentos e da afetividade travada, transforma-se num pacote bêbado, interrompendo o tráfego, categoria que poderia representar a passagem do tempo sem qualidade ou utopia. Cimento e lágrima (matéria bruta e matéria tênue a um só tempo).

Nesta canção, Chico atualiza e dialoga com o seu primeiro grande sucesso, revendo o "pedro pedreiro" que já não espera mais nada. Em Construção não há nostal gia nem utopia. 0 operário sabe que o seu tempo chegou, não como libertação coletiva, mas como tragédia pessoal. 0 primeiro conjunto de estrofes, cantadas numa levada de samba triste, nos revela a figura trágica e autômata do ser, perturbada porém por sinais de uma explosão existencial iminente que se configura. Contra o "desenho lógico" que auto-encerra o ser autômato, restam a loucura e a embriaguez que lhe devolvem a humanidade, ainda que de maneira cruel:

Amou daquela vez como se fosse a última

Beijou sua mulher como se fosse a última

E cada filho seu como se fosse o único

E atravessou a rua com seu passo tímido

Subiu a construção como se fosse máquina

Ergueu no patamar quatro paredes sólidas

Tijolo com tijolo num desenho mágico

O desenho, ao se tranforformar em mágico, sugere o arrebatamento de uma não-consciência, estado próximo da morte, que num não-tempo (o tempo da ditadura) é simulacro de êxtase eliberdade. A drama- 
ticidade patética implode o cotidiano regrado, mas, na verdade, não leva a nenhuma liberdade. Fecha-se assim o dia do operário que, agonizante, interrompe o "tempo vazio e homogêneo":

Seus ol hos embotados de cimento e lágrima

Sentou pra descansar como se fosse sábado

Comeu feijão com arroz como se fosse um príncipe

Bebeu e soluçou como se fosse um náufrago

D ançou e gargalhou como se ouvisse música

E tropeçou no céu como se fosse um bêbado

E flutuou no ar como se fosse um pássaro

E se acabou no chão feito um pacote flácido

Agonizou no meio do passeio público

Morreu na contramão atrapal hando o tráfego

Na segunda parte, paralelamente ao crescendo da orquestra, ${ }_{13}^{13} \mathrm{Cu}$ jos naipes de metais e cordas acentuam progressivamente o tom dramático da canção, o ser retorna num exercício de combinatório poético, com as últimas palavras de cada verso funcionando como tijolos desenhando um quadro cada vez menos lógico.

Amou daquela vez como se fosse a última

Beijou sua mulher como se fosse a única

E cada filho como se fosse o pródigo

E atravessou a rua com seu passo bêbado

Subiu a construção como se fosse sólido

Ergueu no patamar quatro paredes mágicas

Tijolo com tijolo num desenho lógico

Seus olhos embotados de cimento e tráfego

A morte extática do operário perde o tom de dramaticidade, beirando o limite do patético. 0 paroxismo entre o êxtase de uma liberdade fugaz, vivida como simulacro de grandeza e felicidade (príncipe/máximo/máquina/próximo/música/sábado), e a morte agônica e 
insignificante (pacote tímido/passeio náufrago/ atrapalhando o público), se intensifica:

Sentou pra descansar como se fosse um príncipe

Comeu feijão com arroz como se fosse o máximo

Bebeu e soluçou como se fosse máquina

Dançou e gargal hou como se fosse o próximo

E tropeçou no céu como se ouvisse música

E flutuou no ar como se fosse sábado

E se acabou no chão feito um pacote tímido

Agonizou no meio do passeio náufrago

M orreu na contramão atrapalhando o público

Na última estrofe o combinatório das últimas palavras de cada verso realiza a implosão de qualquer sentido lógico do poema, ao mesmo tempo em que é mais reveladora do seu "desenho mágico" e do seu sentido mais propriamente político. 0 problema do ser retorna mais uma vez, adensado na sua antiexperiência pela fragilidade das próprias estruturas da realidade ( "paredes flácidas"). Todas as quatro paredes sólidas do edifício parecem ruir junto com o operário. 0 ser ao negarse, e virtualmente tornar-se não-ser através da morte, consegue no máximo "atrapal har" (verbo reiterado nos últimos versos de cada estrofe) o cotidiano regrado de uma sociedade automatizada. No breve tempo/espaço do delírio e da queda, no entanto, ele toma para si sua própria humanidade.

Amou daquela vez como se fosse máquina

Beijou sua mulher como se fosse lógico

Ergueu no patamar quatro paredes flácidas

Sentou pra descansar como se fosse um pássaro

E flutuou no ar como se fosse um príncipe

E se acabou no chão feito um pacote bêbado

M orreu na contra-mão atrapalhando o sábado 
O tempo em Construção se manifesta em duas dimensões: em primeiro lugar, como iminência, traduzi da pela decisão do operário que decide romper o cotidiano ( ão-tempo) pelo delírio e pela morte; em segundo lugar, o tempo se manifesta como o breve espaço de liberdade entre a decisão de "sentar pra descançar", seguida do êxtase da loucura e arrebatamento da queda. Toda a densidade do ser acumulada ao longo dos versos, traduzidos numa consciência trágica da própria condição, é bruscamente estancada quando o "pacote flácido/ tímido/bêbado" chega ao solo.

\title{
FADO TROPICAL
}

A canção Fado tropical fazia parte da peça Calabar, de 1973, e junto com as outras músicas foi proibida. ${ }^{14} \mathrm{~A}$ matéria, que era trágica em Construção, ganha agora um tom falsamente épico. Falsamente, pois Chico realiza uma estratégia de esvaziamento do discurso histórico épico e ufanista, fazendo surgir poeticamente um tempo histórico enviesado, habitado por ser nacional enviesado: "Brasil, imenso Portugal". A ditadura brasileira e a ditadura salazarista, pródigas em discursos ufanistas, são trabalhadas pela paráfrase crítica. A voz que fala pelo poema assume o discurso do colonizador que se confunde com a própria natureza brasileira, por sua vez, objeto histórico de ideologização nos discursos do poder:

\author{
Oh, musa do meu fado \\ Oh, minha mãe gentil \\ Te deixo consternado \\ No primeiro abril \\ M as não sêtão ingrata \\ $N$ ão esquece quem te amou \\ E em tua densa mata \\ Se perdeu e se encontrou \\ $A i$, esta terra ainda vai cumprir seu ideal \\ Ainda vai tornar-se um imenso Portugal
}


No trecho recitado, o discurso do ser enviesado, na medida em que na verdade é um não-ser, posto que colonizado, se apropria da auto-imagem sentimentalista. $M$ as, ao mesmo tempo, revela a consciência cínica da sua natureza ideológica:

Sabe, no fundo eu sou um sentimental

Todos nós herdamos no sangue lusitano uma boa dose

[de lirismo...(além dasífilis, éclaro)

M esmo quando as minhas mãos estão ocupadas em

[torturar, esganar, trucidar

M eu coração fecha os olhos e sinceramente chora...

Em seguida, novamente a natureza brasileira é objeto do discurso, perpassada por símbolos lusitanos, numa operação sofisticada de aglutinação, marca de um enviesamento da consciência colonizada:

Com avencas na caatinga

Alecrins no canavial

Licores na moringa

Um vinho tropical

E a linda mulata

Com rendas do Alentejo

Dequem numa bravata

Arrebato um beijo

Ai, esta terra ainda vai cumprir seu ideal

Ainda vai tornar-se um imenso Portugal

O corre então um soneto incidental, reforçando o paroxismo entre a alma nostálgica e lírica e a violência da colonização, tomada aqui como metáfora da própria ditadura militar:

M eu coração tem um sereno jeito

E as minhas mãos o golpe duro e presto

Detal maneira que, depois de feito 
Desencontrado, eu mesmo me contesto

Se trago as mãos distantes do meu peito

É que há distância entre intenção e gesto

E se o meu coração nas mãos estreito

Me assombra a súbita impressão de incesto

Quando me encontro no calor da luta

Ostento a aguda empunhadora à proa

Mas o meu peito se desabotoa

E se a sentença se anuncia bruta

M ais que depressa a mão cega executa

Pois que senão o coração perdoa...

N ovamente, os símbolos da natureza e da cultura ideologizadas de Brasil e Portugal se aglutinam, formando uma consciência híbrida, a qual já não distingue quem é o colonizador, quem éo colonizado:

\author{
Guitarras e sanfonas \\ Jasmins, coqueiros, fontes \\ Sardinhas, mandioca \\ Num suave azulejo \\ E o rio Amazonas \\ Que corre Trás-os-M ontes \\ E numa pororoca \\ Deságua no Tejo
}

Ai, esta terra ainda vai cumprir seu ideal

Ainda vai tornar-se um imenso Portugal

$\mathrm{Ai}$, esta terra ainda vai cumprir seu ideal

Ainda vai tornar-se um império colonial

No que o Brasil de fato deve se tornar para cumprir seu ideal de "imenso Portugal": introjetar o império opressor ou a pátria libertada pela revolução? Eis o dilema que a canção deixa no ar, a partir de um deslocamento de sentido sugerido pela ambigüidade da sentença final. 


\section{CORRENTE}

Enquanto Construção e fado tropical expressam o ápice da tensão não-ser e não-tempo, em suas dimensões individual-classista e coletiva-nacional, Corrente, samba alegre e ritmado, pode ser visto como um dos melhores exercícios de mensagem cifrada contra a ditadura. ${ }^{15} \mathrm{Chi}$ co faz o compositor confundir-se com o "eu poético" que, a princípio, parece assumir o seu lugar no "coro dos contentes" da ditadura militar. Parte do álbum M eus caros amigos, de 1976, o samba já apresentava algumas ousadias lúdicas que car acterizariam as canções da "abertura". N este jogo lúdico entre o dizer e o não-dizer, novamente estão operando as categorias do ser e do tempo.

A expressão "samba bem pra frente" já apresenta um posicionamento em relação ao tempo. Lembremos que "pra frente" era uma das expressões ideológicas mais fortes do discurso ufanista dos militares no poder, verdadeira epígrafe da era M édici. M as nesta canção a expressão é invertida, denunciando o falso fluxo da história, cujo sentido é dado pela obrigação de fazer parte do coro dos contentes ("o samba tá bem melhorado"). Como já dissermos, o eu poético que, neste caso, se confunde com o próprio compositor, falsamente une-se a esse coro. Entretanto, destece a própria poesia, como Penélope enganando seu pretendente. N esta canção, Chico Buarque faz o tempo refluir, pois sugere que a melancolia é um antídoto contra o ufanismo eufórico do discurso do poder. Esta afirmativa não é figurada, tomada a partir do conteúdo do poema. A própria estrutura e a disposi ção dos versos realizam a desconstrução do sentido. A chave da decodificação está no próprio título. ${ }^{16}$

Na primeira parte, proposição de assertivas em forma versificada, o sentido parece ser o da autocrítica de um compositor outrora crítico ao regime e ao sistema:

\footnotetext{
Eu hoje fiz um samba bem pra frente

Dizendo real mente o que éque eu acho

Eu acho que o meu samba é uma corrente

E coerentemente assino embaixo

Hojeé preciso refletir um pouco

E ver que o samba está tomando jeito
} 
Só mesmo embriagado ou muito louco

Pra contestar e pra botar defeito

Precisa ser muito sincero e claro

Pra confessar que andei sambando errado

Talvez precise até tomar na cara

Pra ver que o samba está bem melhorado

Tem mais é que ser bem cara de tacho

Não ver a multidão sambar contente

Isso me deixa triste e cabisbaixo

Por isso eu fiz um samba bem pra frente

M as a "corrente pra frente" sutilmente parece refluir para o discurso crítico e desconstrói o tempo do ufanismo que parecia se afirmar na primeira parte. É no segundo verso de cada par que o compositor diz o que ele "realmente acha" da realidade (configurada no verso anterior); mas o primeiro verso seguinte repõe o jogo de esconde-esconde com a ditadura e a censura, sendo negado pelo verso seguinte e assim sucessivamente. Então, como numa corrente, o encadeamento alternado dos elos traduz o verdadeiro sentido da canção:

Dizendo realmente o que é que eu acho

Eu acho que o meu samba é uma corrente

E coerentemente assino embaixo

Hojeé preciso refletir um pouco

E ver que o samba está tomando jeito

Só mesmo embriagado ou muito louco

Pra contestar e pra botar defeito

Precisa ser muito sincero e claro

Pra confessar que andei sambando errado

Talvez precise até tomar na cara

Pra ver que o samba está bem melhorado

Tem mais é que ser bem cara de tacho

Não ver a multidão sambar contente

Isso me deixa triste e cabisbaixo

Por isso eu fiz um samba bem pra frente

Dizendo realmente o que é que eu acho 


\section{O QUE SERÁ}

A canção 0 que será teve duas versões: a flor da terra e à flor da pele. Ambas foram grandes sucessos de 1976/77, principalmente a versão cantada por Chico no álbum M eus caros amigos (Flor da Terra), de andamento mais acelerado ecom ênfase mais épica do que lírica, éuma das maiores expressões poéti cas dos anseios da oposição civil por um novo tempo. Nesta canção Chico Buarque canta a resistência ao regime militar na forma de um amanhã iminente. A ameaça do não-tempo - não ser, produtos da experiência autoritária produtora do silêncio, estaria por um fio.

O fluxo de consciência crítica do ser parece tomado de um arrebatamento. $\mathrm{N}$ ão aquelearrebatamento trágico eautodestrutivo do operário de Construção, mas um arrebatamento quase erótico, quase indizível, posto que é energia acumulada, represada e reprimida, pronta para explodir.

Temos a ocorrência poética de um tempo da irrupção do ser na iminência do gozo da liberdade. Chico expressa, nesta canção, a possibilidade da reconquista da experiência do ser no tempo, no limite de tornar-se consciência, mas ainda experiência confusa, caótica, dilacerada. De maneira contundente, Chico funde desejo e política, indivíduo e soci edade, cabeças e bocas, governo e não-governo, sagrado e profano. Os "poetas delirantes e profetas embriagados" se confundem com a "romaria dos mutilados" e a "fantasia dos infelizes". Sentido e não-sentido. Assim, 0 que será, diferente dos paradigmas mais comuns da canção engajada, não canta a certeza sobre o futuro. Antes, é uma canção de uma era de incertezas, fruto da abertura política vigiada e ainda temerária proposta pelo governo Geisel (1974-1979).

A primeira estrofe aponta para um clima de conspiração, no qual a palavra se mescla ao silêncio. "Que anda na cabeça, anda nas bocas", traduz o movimento da idéia tornando-se palavra, na iminência detornar-se gesto - incontrolável, irrepreensível e imprevisível:

O que será que será

Que andam suspirando pelas alcovas 


\begin{abstract}
Que andam sussurrando em versos e trovas
Que andam combinando no breu das tocas

Que anda nas cabeças, anda nas bocas

Que andam acendendo velas nos becos

Que estão falando alto pelos botecos

Que gritam nos mercados, que com certeza

Está na natureza, será que será

0 que não tem certeza nem nunca terá

O que não tem conserto nem nunca terá

O que não tem tamanho
\end{abstract}

A segunda parte anuncia a forte carga de desejo, transformando a possibilidade de liberdade do ser em estado de êxtase quase erótico, veiculado por linguagens transgressoras, nem sempre lógicas e racionais.
O que será que será
Que vive nas idéias desses amantes
Que cantam os poetas mais delirantes
Quejuram os profetas embriagados
Que está na romaria dos mutilados
Que está na fantasia dos infelizes
Que está no dia-a-dia das meretrizes
No plano dos bandidos, dos desvalidos
Em todos os sentidos, será que será
0 que não tem decência nem nunca terá
O que não tem censura nem nunca terá
0 que não faz sentido

Finalmente, o tempo da iminência transforma-se no tempo da certeza utópica. A irrupção da liberdade, explodindo do desejo, rompe as consciências individuais, sugerindo um ser coletivo e amalgamado na experiência histórica ( "todos os destinos irão se encontrar"). É curioso notar que, enquanto a segunda parte anuncia uma espécie de apocalipse social, com personagens deserdados e transgressores (amantes/romaria dos mutilados/profetas embriagados/ infelizes/meretrizes / plano dos 
bandidos/desvalidos), a terceira parte sugere que este apocalipse necessário ( revolução?) será consagrado até mesmo pelo Padre Eterno, como se fosse o resultado necessário de um plano superior da Providência, ou, em termos mais apropriados para a época, da razão histórica, movimento que iria recolocar o ser social no tempo forte da História.

\section{O que será que será}

Que todos os avisos não vão evitar

Porque todos os risos vão desafiar

Porque todos os sinos irão repicar

Porque todos os hinos irão consagrar

E todos os meninos vão desembestar

$E$ todos os destinos irão se encontrar

E o mesmo Padre Eterno que nunca foi lá

Olhando aquele inferno, vai abençoar

0 que não tem governo nem nunca terá

O que não tem vergonha nem nunca terá

O que não tem juízo

PEDAÇO DE MIM

Entretanto, nem todas as canções de Chico Buarque - da fase da abertura - realizam o reencontro do ser com o tempo. Numa de suas canções mais fortes ${ }^{17}$, Pedaço de mim, Chico sugere o confronto entre 0 lírico e o épico: ser sem tempo quer recuperar o tempo de outro ser que jaz em silencio (Saudade dói latejada / é como uma fisgada / num membro quejá perdi). Anuncia-se a presença de uma ausência que não se realiza como consciência e como experiência (a erfahrung - experiência forte benjaminiana): "arrumar o quarto de um filho quejá morreu". M ais do que nostalgia lírica, fruto da melancolia, ocorre aqui uma paralisia da experiência e do fluxo de tempo. N ovamente a ameaça do não-ser e do não-tempo, vividos deste modo sob o signo da perda ir- 
reparável provocada por uma época de opressão extrema. Paradoxalmente, este sentimento tenta se resolver no ato de dizer "Adeus", revelando a tensão entre "luto" e "melancolia", diante da perda do ser amado (não é por acaso que a também melodia repousa nesta palavra). Não há jactância, ao contrário, a música termina com um sabor de ausência prolongada e irreparável.

Oh, pedaço de mim

Oh, metade afastada de mim

Leva o teu olhar

Q ue a saudade é o pior tormento

É pior do que o esquecimento

É pior do que se entrevar

Oh, pedaço de mim

Oh, metade exilada de mim

Leva os teus sinais

Que a saudade dói como um barco

Que aos poucos descreve um arco

E evita atracar no cais

Oh, pedaço de mim

Oh, metade arrancada de mim

Leva o vulto teu

Que a saudade é o revés de um parto

A saudade é arrumar o quarto

Do filho que já morreu

Oh, pedaço de mim

Oh, metade amputada de mim

Leva o que há de ti

Que a saudade dói latejada

É assim como uma fisgada

No membro que já perdi 
Oh, pedaço de mim

Oh, metade adorada de mim

Lava os olhos meus

Que a saudade éo pior castigo

E eu não quero levar comigo

A mortalha do amor

Adeus

\section{QUESTÕES FINAIS}

Chico Buarque de H ollanda não foi apenas o cronista dos anos de chumbo - aquele que cantou e contou-nos sobre o seu tempo. A obra de Chico nos anos 70 - e sua grande popularidade e importância sociocultural - pode estar ligada a este aspecto - teve a singularidade de cantar a perplexidade do ser (isto é, aquele que tem consciência) no tempo adverso da liberdade sonhada. Tempo de rupturas e crise de utopias (traduzida na idéia de resistência - manter-se vivo sem se projetar no amanhã). Tempo da modernização conservadora que selou um novo destino histórico para o Brasil. A partir de então, toda a inocência ficou proibida, e o Brasil, definitivamente, passou a ser o "País da delicadeza perdida" (que talvez nunca tenha realmente existido...).

N um certo sentido, todos os destinos se encontravam nas canções de Chico, ao menos os de um certo grupo de consciências críticas que marcaram a oposição civil ao regime militar. 0 limite deste gesto era que ele durava, nos anos 60 e 70, a exata medida de uma canção, dado o fechamento da arena pública de atuação política. Na experiência individual e coletiva de ouvir canções, ser e tempo pareciam se reconciliar momentaneamente numa espécie de promessa (ou estado) de felicidade, ainda que fugidia. A obra de Chico expressa radicalmente a gama de experiências do ser no tempo, no contexto particular do Brasil dos anos 60 e 70, mesmo fazendo de sua matéria poética a sombria ameaça do triunfo do não-ser e do não-tempo, enquanto diluição da experiência coletiva da história. Entre um e outro, entre melancolia, 
perplexidade e "promessa de felicidade" revelava-se uma determinada faceta da sociedade civil diante do difícil tempo dos "anos de chumbo".

Na experiência social da M PB daquele contexto, o tempo não operava como monotonia ou imobilidade forçada, mas como iminência de um "novo tempo", ainda que obstaculizado pela experiência da repressão. M as, quando isto ocorria, sempre havia uma canção para consolar e arejar o ouvinte com o bafio da esperança e da liberdade.

NAPOLITANO , M. "Today it is necessary to reflect a little bit": social being and historical time on Chico Buarque de H ollanda's songs. 1971/1978. H istória, São Paulo: v.22, n. 1, pp. 115 a 134, 2003.

A в S T R ACт: This article analyses the connection between social being and historical experience focusing five songs composed by Chico Buarque de Hollanda in the 1970 s, during Brazilian military regime. I argue that the songs of Chico Buarque express many forms of critical conscience about authoritarian experience and the closing of public sphere. In my point of view, Chico's poetical matter is precisely the tension relationship of being and time and, in that sense, overcame the traditional subjects of the protest songs.

KEY WOR Ds: Brazilian popular music: Chico Buarque de Hollanda; music and politics; Brazilian military regime: cultural aspects.

\section{NOTAS}

${ }^{1}$ Departamento de História - Universidade Federal do Paraná - CEP 80060-150 Curitiba - PR.

${ }^{2}$ BOSI, A. 0 ser e o tempo na poesia. São Paulo: Companhia das Letras, 2001.

${ }^{3}$ Idem, p. 167.

${ }^{4}$ M EN ESES, A. D esenho mágico. Poesia e política em Chico Buarque de H ollanda. $2^{a}$ ed. São Paulo: Ateliê Editorial, 1995.

${ }^{5}$ STARLIN G, H. Convite para uma fantasia e um violão. Seminário da Bossa Nova à Tropicália. Rio de Janeiro: Universidade Cândido M endes, maio 2001.

${ }^{6}$ Idem, p.2. 


\section{${ }^{7}$ Idem, p.3.}

${ }^{8}$ Idem, p. 13.

${ }^{9}$ WISNIK, J. M. et al. Anos 70: música. Rio de Janeiro: Europa, 1979.

${ }^{10} \mathrm{O}$ episódio de censura sobre a peça e o disco Calabar, que além de ocasionar a ruína financeira do compositor, também produtor da peça, mergulhou-o numa crise criativa muito grande, da qual se livraria alguns anos depois.

${ }^{11}$ Aspecto notado no texto seminal de GALVÃO, W. M PB: uma análise ideológica. IN : Saco de gatos. São Paulo: Duas Cidades, 1976.

${ }^{12}$ BENJAM IN, W. Um lírico no auge do capitalismo. São Paulo: Brasiliense, 1986.

${ }^{13} \mathrm{O}$ arranjo, parte estrutural da canção, foi feito por Rogério Duprat, dentro da lógica de trilha sonora para as imagens veiculadas pela letra.

${ }^{14}$ Sobre os efeitos da censura na M PB e na obra de Chico em particular, ver MOBY, A. Sinal Fechado. A M PB sob censura. Rio de Janeiro: M ercado Aberto, 1994.

${ }^{15}$ Gilberto Vasconcelos nomeou esta estratégia de "linguagem da fresta". VASCONCELOS, G. M úsica Popular: de olho na fresta. Rio de Janeiro: Graal, 1976.

${ }^{16}$ Ver as análises de PERRON E, C. M asters of contemporary Brazilian song. Austin: University of Texas Press, 1995 e M ENESES, A. Op .cit.

${ }^{17}$ Esta canção parece complementar a homenagem de Chico a Zuzu Angel , já feita em Angélica, mãe de dois militantes mortos sob tortura durante o regime militar e que se tornou símbolo da luta pelos Direitos Humanos, vindo a morrer de forma suspeita.

Artigo recebido em 03/2003. Aprovado em 05/2003. 